\title{
In Situ Endoscopic Analysis of Bone Microstructure and Vascularization in Post-Extraction Sites Immediately After a Minimally Invasive Vertical Tooth Extraction in Teeth with Different Periodontal Status
}

\author{
Análisis Endoscópico in Situ de la Microestructura Ósea y Vascularización en Alvéolos \\ Post-Extracción Inmediatamente Después de una Extracción Dental Mínimamente Invasiva \\ en Dientes con Diferente Estado Periodontal
}

\author{
Daniela Arraño ${ }^{1}$; Alejandra Chaparro ${ }^{1}$; Marcio Lazzarini² \\ Pablo Acuña-Mardones ${ }^{3}$; Wilfried Engelke ${ }^{4,5}$ \& Víctor Beltrán ${ }^{3}$
}

\begin{abstract}
ARRAÑO, D. ; CHAPARRO, A.; LAZZARINI, M.; ACUÑA-MARDONES, P.; ENGELKE, W. \& BELTRÁN, V. In situ endoscopic analysis of bone microstructure and vascularization in post-extraction sites immediately after a minimally invasive vertical tooth extraction in teeth with different periodontal status: A preliminary study. Int. J. Morphol., 38(6):1735-1741, 2020.
\end{abstract}

SUMMARY: The aim of this study was to perform an in situ endoscopic analysis of the vascularization of post-extraction sites immediately after a non-traumatic extraction in terms of the number of blood vessels per field (NBV), relative area of blood vessels (RABV) and relative area of unmineralized bone (RAUB) in teeth with different periodontal status (PS). This assessment was performed using short distance support immersion endoscopy (SD-SIE). Ten patients (4 men/ 6 women, aged between 25 and 44 ) were selected. From them, 10 teeth were extracted due to periodontal reasons or other motives. These teeth were then categorized into 2 groups according to their PS, either as periodontally compromised (PC) (clinical attachment loss (CAL) $>7$ mm and probing depth (PD) $>5$ $\mathrm{mm}$ ) or periodontally healthy $(\mathrm{PH})(\mathrm{CAL}<7 \mathrm{~mm}$ and $\mathrm{PD}<5 \mathrm{~mm}$, without bleeding or suppuration during periodontal probing), and mobile (M) (> $1 \mathrm{~mm}$ horizontally) or immobile (I) $(<1 \mathrm{~mm}$ horizontally). The minimally invasive vertical tooth extractions were performed using the Benex ${ }^{\circledR}$ extractor. Immediately after extraction, a rigid immersion endoscope with a diameter of $2.7 \mathrm{~mm}$ was introduced, and a video-alveoloscopy was carried out. This video was analyzed by ImageJ software for the quantification of NBV, RABV and RAUB per field of the post-extraction sites with different PS (PC, PH, M, I) were quantified. In the PC group, significantly greater values for RAUB were observed $(33.45 \%$ ) compared to those from the PH group (19.65\%). Compared with the M group, the I group did not show significant differences in terms of RAUB or RABV . There were also no differences in NBV in both groups (Means: 33.8 vs. 30.5 , respectively).

KEY WORDS: Extraction socket; Endoscopy; Microsurgical removal; Bone vascularization.

\section{INTRODUCTION}

Exodontia is one of the most important and common procedures in modern dentistry and it is also the most frequent surgical intervention into human bone (Engelke $e t$ al., 2015). Currently, considerable research has been carried out regarding the expected dimensional changes in the bony walls of the alveoli after the tooth extraction. In this sense, both animal and human models have shown that the resorption of the vestibular and lingual walls of the alveolus occurs in two overlapping phases (Araújo \& Lindhe, 2005, 2009; Misawa et al., 2016). During the first phase, the bundle bone, i.e. the cribriform bone tissue immediately adjacent to the tooth inside the alveolus, is reabsorbed and replaced with woven bone as the former loses its function following tooth extraction. Due to the fact that the crest of the vestibular

\footnotetext{
${ }^{1}$ Universidad de Los Andes, Department of Periodontology, Faculty of Dentistry, Universidad de los Andes, Santiago, Chile.

${ }^{2}$ Max Planck Institute of Experimental Medicine, Department of Molecular Biology of Neuronal Signals, Göttingen, Germany.

${ }^{3}$ Universidad de La Frontera, Dental School, Clinical Investigation and Dental Innovation Center (CIDIC) and Center for Translational Medicine (CEMTBIOREN), Temuco, Chile.

${ }^{4}$ Department of Oral and Maxillofacial Surgery, Georg-August-University Hospital, Göttingen, Germany.

${ }^{5}$ Universidad de La Frontera, Center of Physics and Engineering in Medicine (CFIM), Faculty of Engineering and Sciences, Temuco, Chile.
} 
ARRAÑO, D. ; CHAPARRO, A.; LAZZARINI, M.; ACUÑA-MARDONES, P.; ENGELKE, W. \& BELTRÁN, V. In situ endoscopic analysis of bone microstructure and vascularization in postextraction sites immediately after a minimally invasive vertical tooth extraction in teeth with different periodontal status: A preliminary study. Int. J. Morphol., 38(6):1735-1741, 2020.

bone wall is composed only of bundle alone, this modeling results in a substantial vertical reduction of the vestibular crest (Araújo et al., 2015; Anwandter et al., 2016). In the second phase, resorption occurs on the outer surfaces of both bony walls and healing lasts at least 3 months but may continue for up to one year (Araújo et al.). Based on the findings of these studies and others (Tan et al., 2012), it has been suggested that the healing of the alveolus is directly influenced by the extension of surgical trauma during the procedure and by individual biological differences, such as the size of the alveolus and its degree of vascularization (Engelke et al.; Juodzbalys et al., 2008; Engelke \& Beltrán, 2014; Beltrán et al., 2014). The vascularization of an alveolus has been shown to be a vital factor determining tissue healing and regrowth (Tomlinson \& Silva, 2013; Filipowska et al., 2017).

However, paradoxically, little research has focused on the anatomical variants that exist within the alveoli and on how vascularization influences the reparative capacity of an alveolus (Araújo et al.). Existing studies that analyze the anatomy of the blood vessels in this area have been carried out in human cadavers and in animals (Dempster \& Enlow, 1959; Pizzutto et al., 2006; Al-Hezaimi et al., 2011; Varga et al., 2014; Ito et al., 2015). Yet, we still do not know the number of vessels and medullary spaces in each alveolus at the time of exodontia. In this context, only two recent studies were found that involved an in vivo analysis of alveoli vascularization using endoscopic instruments of high magnification (Engelke et al.; Beltrán et al., 2019). However, both studies focused mainly on a new methodology of in vivo analysis involving post-extraction sockets with an emphasis on the preparation of osseous beds for the installation of endosseous implants. They did not place much importance on the previous clinical characteristics of the bone sites evaluated. These clinical characteristics are important when performing extractions, especially if the clinician is considering is considering, for example, replacing periodontally compromised teeth. No literature was found regarding the in vivo analysis of alveolus vascularization in compromised periodontal tissue in humans. In this context, several decades ago, Egelberg (1967) conducted an interesting study on neoangiogenesis and vascular permeability in the periodontium in an animal model. This study provides necessary information for the understanding of the process of periodontitis and information that aids in making clinical decisions based on the need for regenerative treatments.

The aim of this study was to perform an in situ endoscopic analysis of the vascularization of post-extraction sites immediately after a non-traumatic tooth extraction in terms of number of blood vessels per field (NBV), relative area of blood vessels (RABV) and relative area of unmineralized bone (RAUB) in teeth with different periodontal status. This evaluation was performed using an in vivo assessment via short distance support immersion endoscopy (SD-SIE) which was then analyzed in an offline manner.

\section{MATERIAL AND METHOD}

Ten patients ( 4 men / 6 women, aged between 25 and 44) who attended the dental school clinic of Universidad de La Frontera in Temuco, Chile, were selected according to the following criteria: patients over 18 years of age, presence of teeth requiring tooth extraction for periodontal reasons (maximum one tooth per patient), presence of teeth requiring extraction for non-periodontal reasons: root and crown remnant not suitable for rehabilitation, orthodontic indications (non-impacted tooth), among others (maximum one tooth per patient). Patients were excluded from the study if they met the following criteria: systemic conditions that may alter the reparative response or alterations in coagulation, smokers and those exhibiting poor control of bacterial plaque. Ten teeth, either uni- or bi-radicular, were selected among these patients according to the aforementioned criteria (Fig. 1A).

This study was approved by the Scientific Ethics Committee of the University of La Frontera Folio N ${ }^{\circ} 011$ 17, and participating patients voluntarily signed an informed consent form. The same treatment protocol was carried out throughout the study for all the patients. Indications before and after the surgery were explained orally and in writing and these instructions were the same for all patients. Each patient was subject to a clinical and radiographic evaluation of the tooth to be operated.

Periodontal status was evaluated for the probing depth (PD) and the clinical attachment loss (CAL) by using a North Carolina periodontal probe. Tooth mobility (TM) prior to surgery was evaluated by using two rigid instruments by the same examiner. No medication was given prior to surgery. The variables analyzed in this study were dichotomous and quantitative. The dichotomous variables were: Compromised periodontal tissue around the tooth, which was defined as either periodontally compromised (PC) for teeth with an CAL of $\geq 7 \mathrm{~mm}$ and a PD of $\geq 5 \mathrm{~mm}$, or as periodontally healthy (PH) for teeth with values lower than those and without bleeding or suppuration during periodontal probing. Teeth were also categorized based on TM: mobile (M) was defined as a tooth movement $\geq 1 \mathrm{~mm}$ horizontally and / or vertically, and immobile (I) for all lower values. This was measured 

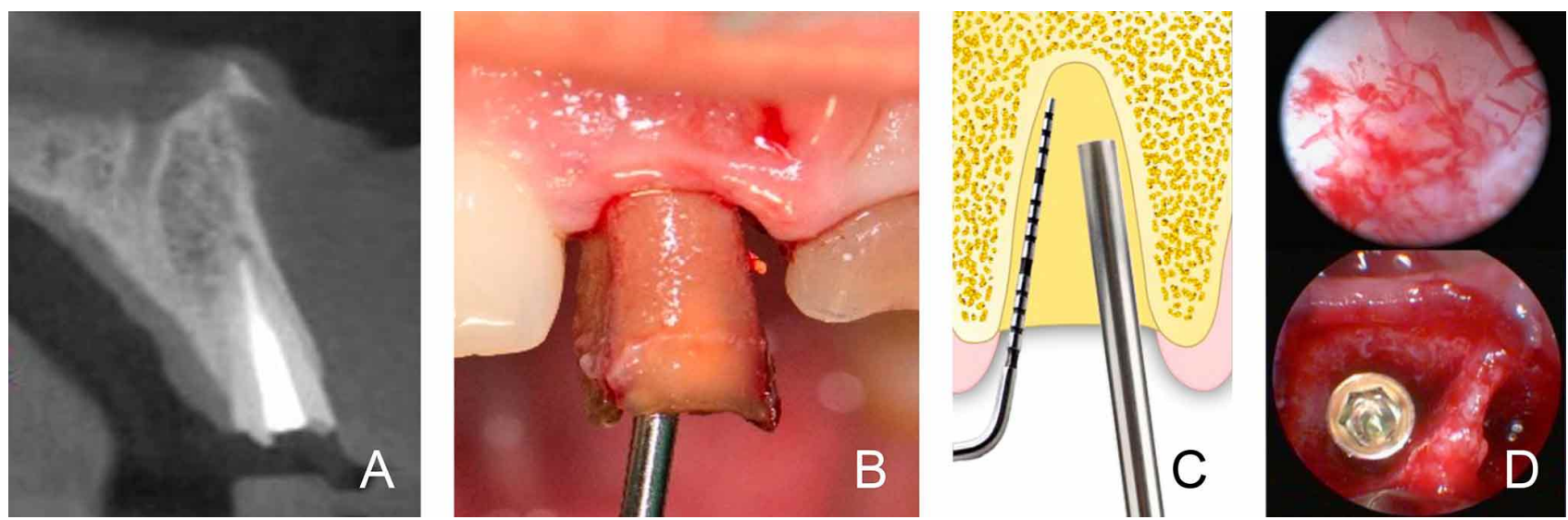

Fig. 1. A: CBTC of tooth 1.1 prior to tooth extraction. B: non-traumatic vertical tooth extraction using the Benex II® system, which maintains the integrity of the alveolar walls. C: Endoscopic contact evaluation of the apical area of the alveolus immediately after tooth extraction prior to alveolar curettage (SD-SIE alveoloscopy). D: Screenshot obtained from the SD-SIE alveoloscopy and immediate placement of a dental implant (Biohorizons tapered, USA).

using two blunt instruments, one for moving and the other for holding the crown or the crown remnant. The quantitative variables considered were the NBV, RAUB and RABV (Tables I and II).

Alveoloscopy procedure by SD-SIE: The surgical procedure was performed under the following standardized care protocol for all patients: use of $2 \%$ infiltrative anesthesia and use of the minimally invasive extractor Benex II ${ }^{\circledR}$ system (Germany) for the vertical non-traumatic exodontia of teeth (Fig. 1B). Then, the alveolus was explored under high magnification microsurgical system, i.e. immediately following the extraction using a rigid endoscope of $2.7 \mathrm{~mm}$ in diameter (Karl Storz, Tuttlingen, Germany) and internal irrigation. This tool allowed viewing of the area at $30^{\circ}$ and $70^{\circ}$ angles with continuous saline irrigation through a support tube (Fig. 1C). The endoscope was used at a short distance to the field of interest, allowing a total inspection of the post-

Table I. Continuous variables according to tooth mobility.

\begin{tabular}{lllll}
\hline Variable & Mobile & \multicolumn{3}{c}{ Immobile } \\
& Mean & SD & Mean & SD \\
\hline NBV & 30.5 & 25.5 & 33.8 & 24 \\
RABV & $0.66 \%$ & $0.54 \%$ & $0.52 \%$ & $0.10 \%$ \\
RAUB & $23.40 \%$ & $15.47 \%$ & $24.23 \%$ & $8.99 \%$ \\
\hline
\end{tabular}

Table II. Continuous variables according to periodontal health.

\begin{tabular}{|c|c|c|c|c|}
\hline \multirow[t]{2}{*}{ Variable } & \multicolumn{2}{|c|}{ Periodontally healthy } & & \multirow{2}{*}{$\begin{array}{c}\text { Periodontally } \\
\text { compromised } \\
\text { SD }\end{array}$} \\
\hline & Mean & SD & Mean & \\
\hline $\mathrm{NB}$ & 26 & 21 & 45 & 24.5 \\
\hline & & & $0.60 \%$ & \\
\hline RAUB & $19.65 \%$ & $9.27 \%$ & $33.45 \%$ & $7.07 \%$ \\
\hline
\end{tabular}

extraction site (Fig. 1D). The observation field was positioned as closely as possible to the surface of the bone tissue of the alveolus in the apical and vestibular area, which was the area randomly selected for analysis. A SD-SIE was then performed. The protocol of this procedure consisted of first having a general view of the bone internal surface and then selecting the area of interest with a magnification up to 40X, during approximately 10 minutes, using intermittent irrigation to clean the pollution at the bleeding bone site.

Finally, postoperative indications were given to the patient both verbally and in writing. Follow-up visits were carried out after one week in order to ensure a normal healing process and to confirm the absence of infection.

Microscopic analysis of alveoloscopy: The analysis of the alveoli after exodontia was performed using the steps laid out in the methodology described by Engelke et al. and Beltrán et al. (2019). First, the video of the alveoloscopy was recorded, which was then analyzed off-line by using the ImageJ software.

Off-line, each video was analyzed by the same technician and the video that best reproduced the area of interest during the alveoloscopy was then selected. The identification of blood capillaries and vascularization was determined through intraoperative bleeding. Thus, the video that reproduced the bleeding sites with greater precision and, following the irrigation of the site with saline solution, showed less bleeding around the structures to be analyzed was selected. After the selection of the most appropriate video for the quantification of blood vessels and unmineralized bone, the video was paused over the area of interest at a time when there was minimal bleeding to 
identify the bone microstructure of the alveolus site. Still images of each area were then taken (screenshots). For each video recorded in the area of interest, the largest possible number of images was taken for analysis, with a minimum of 2 images taken.

The analysis of the selected images was carried out using ImageJ software. The analysis protocol involved first transforming each image into a gray scale image with increased contrast and reduced brightness, improving the

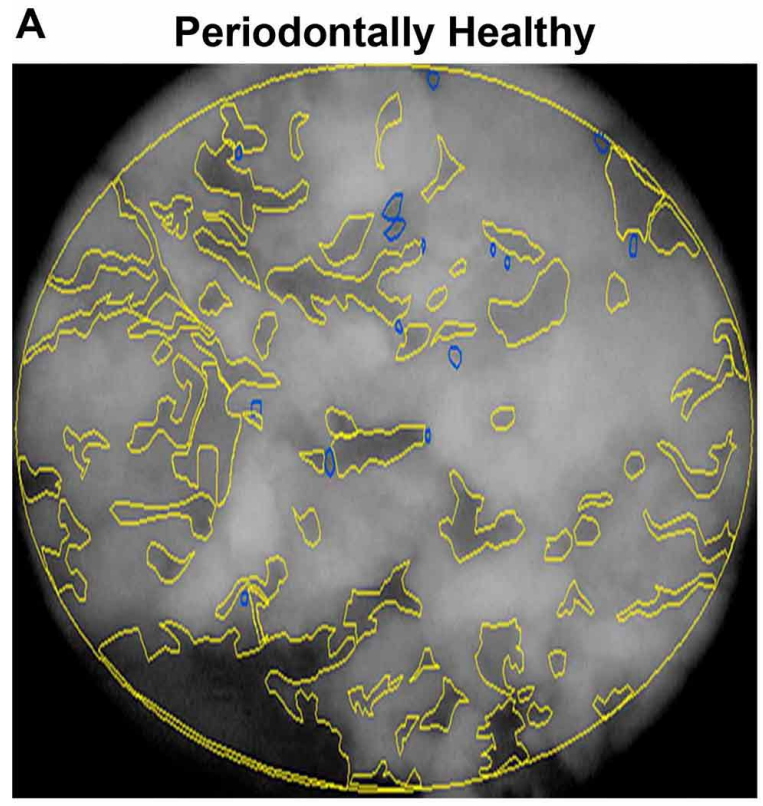

C

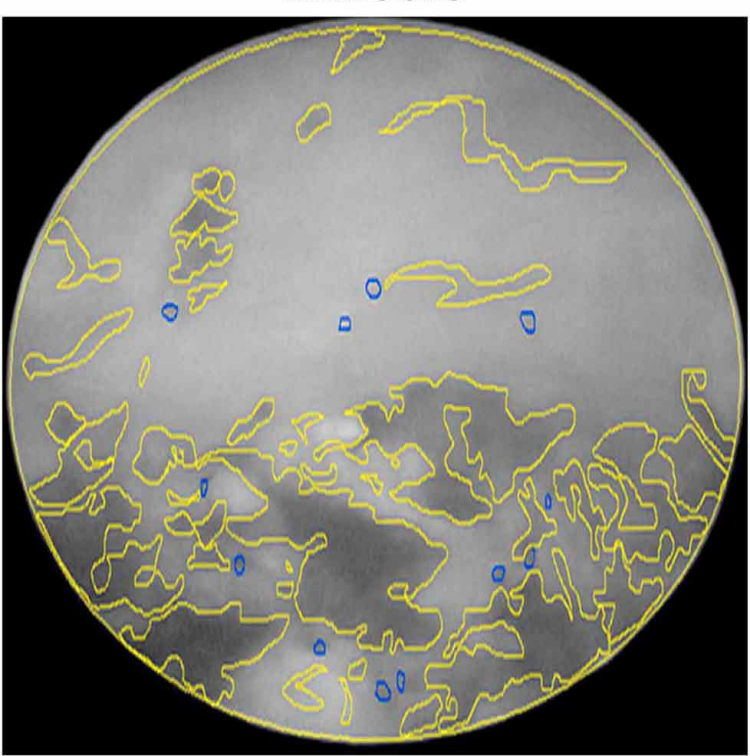

definition of the edges of the vessels shown in the image. Then, using the circular selection tool, the total diameter of the image or area of ??interest was selected, which determined the work circle (quantified as value number 1) and the total area of this circle was recorded. The freehand selection tool was also used to determine blood vessel location and their perimeter and the area of each blood vessel was recorded. Then, the unmineralized bone were recorded with the same freehand selection tool and the area of each of these was recorded (Fig. 2).
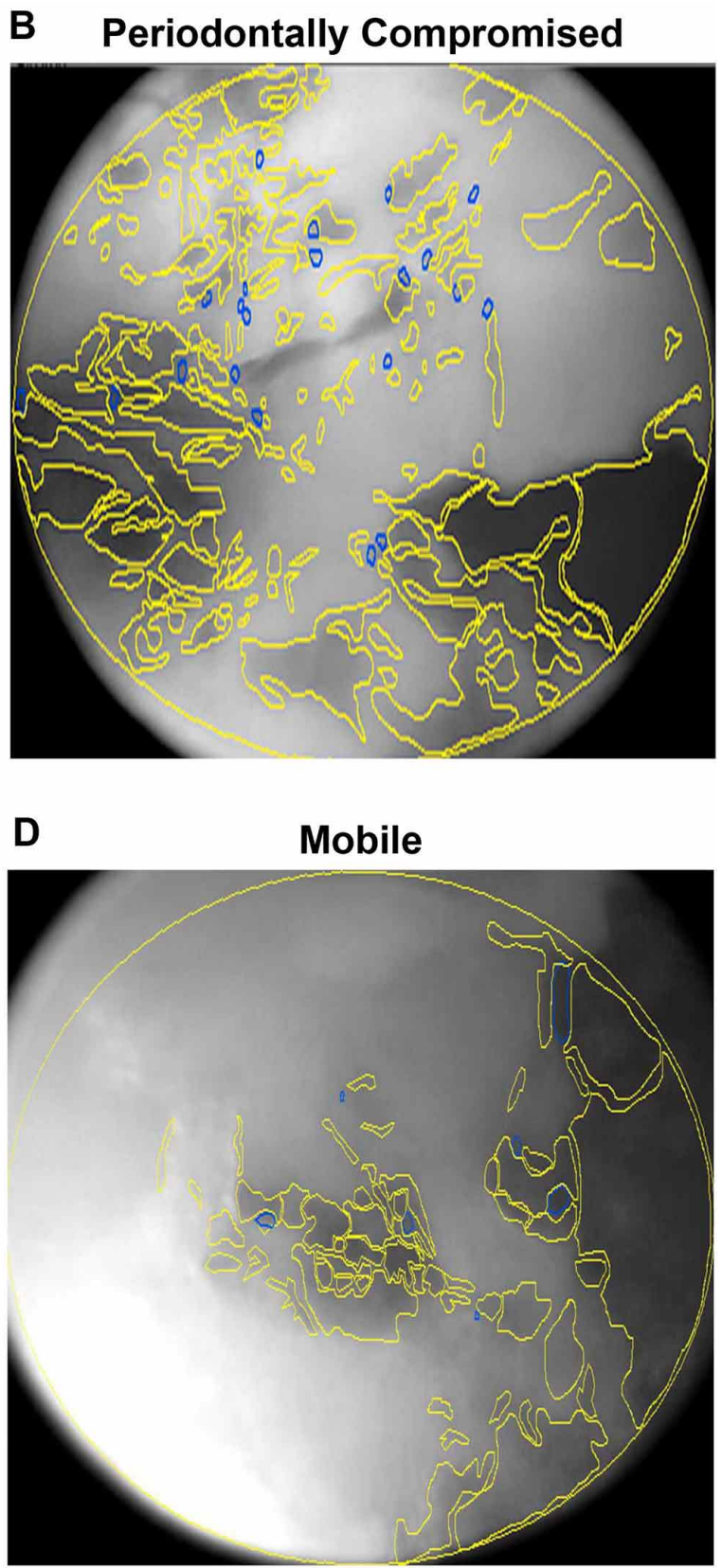

Fig. 2. Bone microstructure analysis conducted in vivo: Images of SD-SIE alveoloscopies using ImageJ software for groups: I. Periodontally healthy, II. Periodontally compromised, III. Immobile and IV. Mobile. Unmineralized bone is marked in yellow and blood vessels are marked in blue through ImageJ software. 
The NBV was quantified by ImageJ software. Similarly, the percentages of RABV and RAUB were calculated. All quantification information and the area of each video was recorded into Tables and separated according to the variables of PH and TM for analysis.

The analysis was made between the alveolus variables of extracted teeth that were $\mathrm{PC}$ and $\mathrm{PH}$, as well as between the alveoli of extracted teeth that were classified as TM and IT through of an independent t-test conducted by means of Stata software, calculating a significant $\mathrm{p}$-value $(<0.05)$.

\section{RESULTS}

Microscopic analysis of bone tissue based on SDSIE alveoloscopy allowed for the identification of NBV, RAUB and RABV in extraction sockets. Among the group of periodontally compromised teeth, significantly greater values of RABV were observed $(33.45 \%)$ when compared to the group of teeth classified as PH (19.65\%). Nevertheless, no differences were observed in the RABV (Independent ttest; * p <0.05) (Fig. 3 A and B). However, the NBV was higher in alveolar post-extraction bone sites of periodontally compromised teeth compared to the alveoli of the periodontally healthy teeth (Mean of $45 \%$ vs. $26 \%$ ).

Compared with the I group, the $\mathrm{M}$ group did not show significant differences in terms of the RAUB or RABV. There were also no differences in NBV of both groups (Mean of 33.8 vs. 30.5 , respectively).

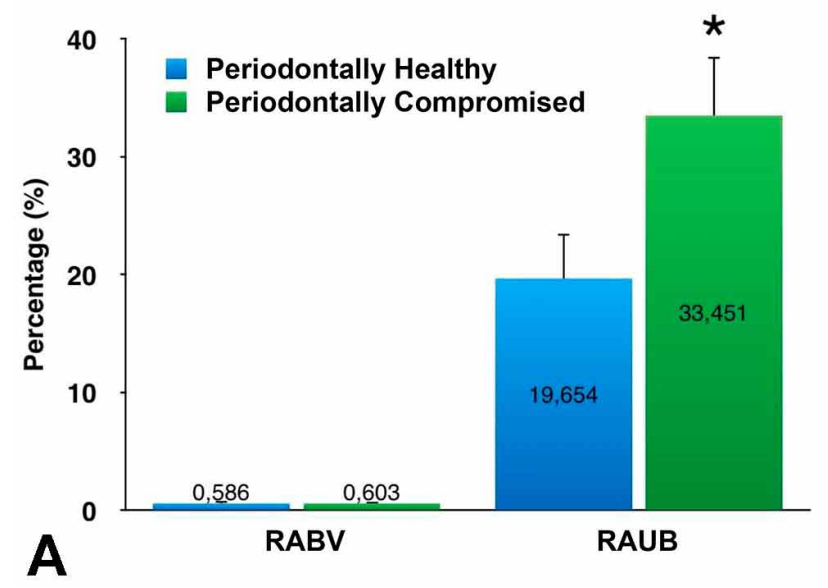

\section{DISCUSSION}

During the investigation, an in situ assessment of the bone microstructure and vascularization of post-extraction sockets immediately after a flapless tooth extraction was performed. In this context, a comparison of the NBV, RABV and RAUB in relation to periodontal status was analyzed.

In comparison to the study performed by Engelke $e t$ al., in which RABV was also analyzed by supported immersion endoscopy in post-extraction sockets and during the preparations of implant sites in native bone prior to the installation of dental implants, values of $1.81 \%$ and $0.58 \%$ (Independent $\mathrm{t}$ test; $\mathrm{p}<0.05$ ) respectively were found, which are slightly higher than the values reported in this study. However, in the group of PC teeth, significantly greater values were observed for the RAUB in the areas analyzed (33.45\%) compared to teeth in the PH group $(19.65 \%$ ) (Independent $\mathrm{t}$ test; $\mathrm{p}<0.05)$. This result is related to the fact that periodontal disease also results in the destruction of existing bone support (Van Der Weijden et al., 2009; Anwandter et al.; Zhao et al., 2018). In addition, during the extraction procedure, the detachment of the cribriform plate can occur in the most apical area due to the fact that the tooth is strongly attached to the alveolus through the fibers of the periodontal ligament. After exodontia, the bundle bone in the site will obviously lose its function and disappear (Araújo \& Lindhe, 2005, 2009; Tan et $a l$.). Thus, these higher values were expected. Another possible theory that can explain a greater quantification of RAUB in the post-extraction sockets of PC teeth may be due to localized resorption processes of the intern cribriform plate resulting from the excessive occlusal trauma these teeth receive.

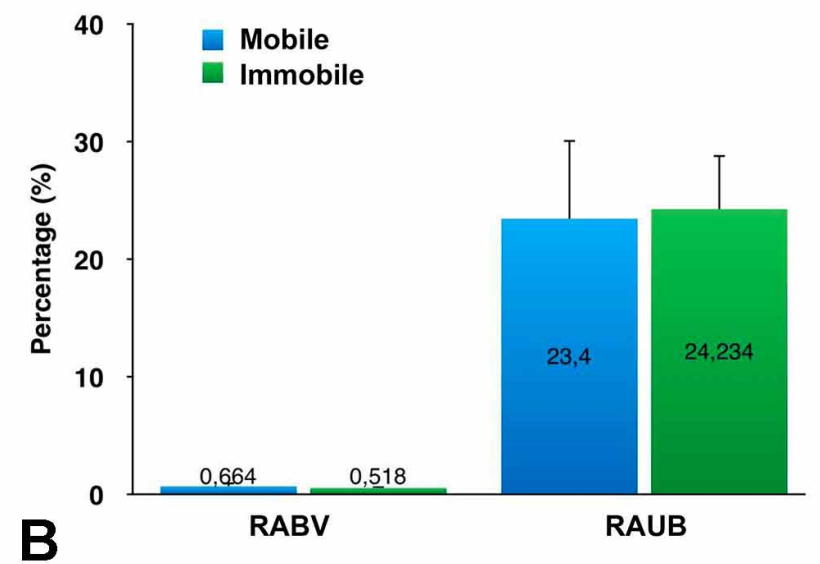

Fig. 3. A: Quantitative analysis of relative areas of unmineralized bone (RAUB) and blood vessels (RABV). The analysis of the postextraction site in periodontally compromised teeth showed greater areas of unmineralized bone compared to the one of periodontally healthy extracted teeth. However, there were no differences in relation to blood vessel area (Independent $\mathrm{t}$ test; * $\mathrm{p}<0.05$ ). B: Quantitative analysis of RAUB and RABV. The analysis of the post-extraction site of mobile vs. immobile did not show significant differences in relation to the RABV and the RAUB (Independent $t$ test; * $\mathrm{p}<0.05$ ). 
ARRAÑO, D. ; CHAPARRO, A.; LAZZARINI, M.; ACUÑA-MARDONES, P.; ENGELKE, W. \& BELTRÁN, V. In situ endoscopic analysis of bone microstructure and vascularization in postextraction sites immediately after a minimally invasive vertical tooth extraction in teeth with different periodontal status: A preliminary study. Int. J. Morphol., 38(6):1735-1741, 2020.

Similarly, the results obtained in this study are alike to those described in the literature that were performed on human cadavers and animal models. In this sense, AlHezaimi et al. studied the causes of bone resorption after tooth extractions in monkeys and concluded that there will be trauma during the extraction that probably damages the alveolus and results in cuts or occlusion of the blood vessels. Therefore, the main factors that affect bone resorption would be the blood supply of the interdental bone and the presence of both the bundle bone and the cortical bone. Considering that it is mainly the interdental portion of a $\mathrm{PC}$ tooth that is affected (Al-Hezaimo et al., 2011), decreasing the cortical bone support in this area, it is pertinent to think that these results, particularly in relation to an increased RAUB in periodontally compromised teeth, are likely accurate.

On the other hand, the results of the RABV were not significant in this study, $0.60 \%$ for the PC group, and 0.58 $\%$ for the PH group (Independent t test; $\mathrm{p}<0.05$ ). The value for the PC teeth was expected to be higher, given that the existing literature includes studies regarding other sectors of the human body and in classic studies of animal models of the periodontium which have shown that chronic inflammation, which occurs alongside periodontitis, generates greater vascularization, permeability and neoangiogenesis of blood vessels (Egelberg; Mavropoulos et al., 2007; Tomlinson \& Silva; Filipowska et al.). This may be due to the fact that the sample size is small, meaning that increasing it could lead to more definitive conclusions regarding this variable.

In relation with the possible effect of a non-traumatic vertical extractor such as Benex II $\AA$, it could be expected that the device produces a pulling force opposite to the orientation of the periodontal fibers, which especially affects the more apical portion of teeth that do not exhibit mobility. This could induce a partial detachment in some areas from the cribriform plate, which can expose the basal spongy bone at the moment of alveolar endoscopic examination immediately after tooth extraction. However, the M group did not show significant differences when compared to the I group, in the RAUB (23.40\% vs. $24.23 \%$ respectively), nor in the RABV $(0.66 \%$ vs. $0.51 \%)$. But we must have in consideration, that this is a pilot study and that the sample size should be increased in future investigations.

The clinical significance of this study is reflected in the fact that prior information on periodontal status can be associated with a specific bone microarchitecture, but apparently not with the vascular supply during in situ postextraction sockets examinations. Therefore, if we extrapolate this information to a clinical setting, teeth that are periodontally compromised should be targeted for some clinical regenerative procedure following tooth extraction to avoid large dimensional changes in the future that result following the extraction of teeth with less bone tissue and more unmineralized bone spaces (Van der Weijden et al.; Zhao et al.).

One recent study by Beltrán et al. (2019) used the same methodology of SD-SIE to compare the quality of regenerated bone in healed post-extraction sites, which are grafted with an in situ hardening b-TCP, against ungrafted sites or native bone, before implant placement. This assessment was also based on microscopic bone analysis in combination with the blood vessel count. They concluded that the regenerated bone in b-TCP grafted extraction sockets showed an increased vascularization compared to ungrafted sites, providing a vital support for subsequent implant placement. This represents an interesting new approach for in situ assessment of bone quality and blood supply before implant placement. Furthermore, if we extrapolate the information of both studies to a clinical setting, we could infer that teeth that are PC and receive a graft could avoid large dimensional spaces and provide an appropriate vital support for a dental implant.

For future studies, increasing the sample size and using the same research method to quantify the RAUB and RABV is recommended. In addition, investigating the clinical influence of the results obtained in this study to PC teeth with higher values of RAUB should be the focus of future studies that could also explore the response of these post-extraction socket to different bone regeneration techniques in the shortterm and determine if there is a decrease in the dimensional changes expected over the long-term.

ARRAÑO, D. ; CHAPARRO, A.; LAZZARINI, M.; ACUÑA-MARDONES, P.; ENGELKE, W. \& BELTRÁN, V. Análisis endoscópico in situ de la microestructura ósea y vascularización en alvéolos post-extracción inmediatamente después de una extracción dental mínimamente invasiva en dientes con diferente estado periodontal. Int. J.Morphol., 38(6):17351741, 2020.

RESUMEN: El objetivo de este estudio fue realizar un análisis endoscópico in situ de la vascularización de los alvéolos post-extracción inmediatamente después de una extracción atraumática en términos de número de vasos sanguíneos por campo de observación (NBV), área relativa de vasos sanguíneos (RABV) y el área relativa de espacios no mineralizados (RAUB) en dientes con diferente estado periodontal (PS). Esta evaluación se realizó mediante endoscopía de inmersión de corta distancia (SD-SIE). Se seleccionaron diez pacientes (4 hombres / 6 mujeres, con edades comprendidas entre 25 y 44). De ellos, se extrajeron 10 dientes debido a razones periodontales u otros motivos. Estos dientes se clasificaron en 2 grupos según su PS, ya sea como periodontalmente comprometidos (PC), los que 
presentaban un nivel de inserción clínica $(\mathrm{CAL}) \geq 7 \mathrm{~mm}$ y una profundidad de sondaje $(\mathrm{PD}) \geq 5 \mathrm{~mm}$; o periodontalmente sanos (PH) (CAL $<7 \mathrm{~mm}$ y PD $<5 \mathrm{~mm}$, sin sangramiento o supuración durante el sondaje periodontal). También se categorizaron según su movilidad como móvil (M) ( $\geq 1 \mathrm{~mm}$ horizontalmente) o inmóvil (I) $(<1 \mathrm{~mm}$ horizontalmente). Las extracciones verticales mínimamente invasivas se realizaron con el extractor Benex ${ }^{\circledR}$. Inmediatamente después de la extracción, se introdujo un endoscopio rígido de inmersión con un diámetro de $2.7 \mathrm{~mm}$, con el cual se realizó una video-alveoloscopía. Este video fue analizado por el software ImageJ para la cuantificación de NBV, RABV y RAUB por campo, de los alvéolos post-extracción con diferente estado periodontal. En el grupo de dientes PC, se observaron valores significativamente mayores para RAUB (33.45 $\%)$ en comparación con los del grupo PH (19.65\%). En comparación con el grupo $\mathrm{M}$, el grupo I no mostró diferencias significativas en términos de RAUB o RABV. Tampoco hubo diferencias en el NBV en ambos grupos (Media: 33.8 frente a 30.5, respectivamente).

PALABRAS CLAVE: Endoscopía; Vascularización; Periodontal.

ACKNOWLEDGEMENTS. This study was funded in part by the DIUFRO projects DI17-0170 and DIE17-0002. Additionally, the authors VB and AC received funding from the project awarded during the second "Inicia tu Idea UfroUAndes" contest. Author WE was financed by the project Folio PAI80160012, CONICYT-Chile.

\section{REFERENCES}

Al-Hezaimi, K.; Levi, P.; Rudy, R.; Al-Jandan, B. \& Al-Rasheed, A. An extraction socket classification developed using analysis of bone type and blood supply to the buccal bone in monkeys. Int. J. Periodontics Restorative Dent., 31(4):421-7, 2011.

Anwandter, A.; Bohmann, S.; Nally, M.; Castro, A. B.; Quirynen, M. \& Pinto, N. Dimensional changes of the post extraction alveolar ridge, preserved with Leukocyte- and Platelet Rich Fibrin: A clinical pilot study. J. Dent., 52:23-9, 2016.

Araújo, M. G. \& Lindhe, J. Dimensional ridge alterations following tooth extraction. An experimental study in the dog. J. Clin. Periodontol., 32(2):212-8, 2005.

Araújo, M. G. \& Lindhe, J. Ridge alterations following tooth extraction with and without flap elevation: an experimental study in the dog. Clin. Oral Implants Res., 20(6):545-9, 2009.

Araújo, M. G.; Silva, C. O.; Misawa, M. \& Sukekava, F. Alveolar socket healing: what can we learn? Periodontol. 2000, 68(1):122-34, 2015.

Beltrán, V.; Cantín, M.; Borie, E.; Fuentes, R. \& Engelke, W. Endoscopic removal of a supernumerary premolar in the mandible during a dental implant placement. Case Rep. Dent., 2014:975470, 2014.

Beltrán, V.; Lazzarini, M.; Figueroa, R.; Sousa, V.; Engelke, W. \& Sartori, M. In situ endoscopic analysis of vascular supply and regenerated alveolar bone in b-TCP grafted and ungrafted postextraction sites before implant placement: A prospective case control study. Biomed. Res. Int., 1(1):1-8, 2019.

Dempster, W. T. \& Enlow, D. H. Patterns of vascular channels in the cortex of the human mandible. Anat. Rec., 135:189-205, 1959.
Egelberg, J. The topography and permeability of vessels at the dentogingival junction in dogs. J. Periodontal Res. Suppl., 1:1-39, 1967.

Engelke, W. \& Beltrán, V. Endoscopic Techniques in Minimally Invasive Oral Surgery. Tuttlingen, Endo Press, 2014.

Engelke, W.; Lazzarini, M.; Stühmer, W. \& Beltrán, V. Support immersion endoscopy in post-extraction alveolar bone chambers: a new window for microscopic bone imaging in vivo. PLoS One, 10(12):e0145767, 2015.

Filipowska, J.; Tomaszewski, K. A.; Niedz'wiedzki, ?; Walocha, J. A. \& Niedz'wiedzki, T. The role of vasculature in bone development, regeneration and proper systemic functioning. Angiogenesis, 20(3):291302, 2017.

Ito, Y.; Fujita, H.; Kanou, M.; Takahashi-Nakagawa, Y.; Nakajima, Y.; Sunano, A.; Kimura, Y. \& Ueno, T. Rapid and easy histological evaluation of alveolar human bone quality at dental implant sites using a nondecalcified frozen cryofilm section technique: a technical report. Implant Dent., 24(4):477-9, 2015.

Juodzbalys, G.; Bojarskas, S.; Kubilius, R. \& Wang, H. L. Using the support immersion endoscope for socket assessment. J. Periodontol., 79(1):6471, 2008.

Mavropoulos, A.; Brodin, P.; Rösing, C. K.; Aass, A. M. \& Aars, H. Gingival blood flow in periodontitis patients before and after periodontal surgery assessed in smokers and non-smokers. J. Periodontol., 78(9):1774-82, 2007.

Misawa, M.; Lindhe, J. \& Araújo, M. G. The alveolar process following single-tooth extraction: a study of maxillary incisor and premolar sites in man. Clin. Oral Implants Res., 27(7):884-9, 2016.

Pizzutto, C. S.; Guimarães, M. A. B. V. \& Mariana, A. N. B. Arterial vascularization of the mandible and maxilla of neotropical primates. Am. J. Primatol., 68(8):777-88, 2006.

Tan, W. L.; Wong, T. L. T.; Wong, M. C. M. \& Lang, N. P. A systematic review of post-extractional alveolar hard and soft tissue dimensional changes in humans. Clin. Oral Implants Res., 23 Suppl. 5:1-21, 2012.

Tomlinson, R. E. \& Silva, M. J. Skeletal blood flow in bone repair and maintenance. Bone Res., 1(4):311-22, 2013.

Van der Weijden, F.; Dell'Acqua, F. \& Slot, D. E. Alveolar bone dimensional changes of post-extraction sockets in humans: a systematic review. J. Clin. Periodontol., 36(12):1048-58, 2009.

Varga, R.; Janovszky, Á.; Szabó, A.; Garab, D.; Bodnár, D.; Boros, M.; Neunzehn, J.; Wiesmann, H. P. \& Piffkó, J. A novel method for in vivo visualization of the microcirculation of the mandibular periosteum in rats. Microcirculation, 21(6):524-31, 2014.

Zhao, L.; Xu, T.; Hu, W. \& Chung, K. H. Preservation and augmentation of molar extraction sites affected by severe bone defect due to advanced periodontitis: A prospective clinical trial. Clin. Implant Dent. Relat. Res., 20(3):333-44, 2018.

Corresponding author:

Prof. Víctor Beltrán

Dental School

Universidad de La Frontera

Manuel Montt № 112

Temuco

CHILE

E-mail: victor.beltran@ufrontera.cl

Received: 07-06-2020

Accepted: 07-08-2020 